\title{
A POESIA CONTEMPORÂNEA EM SUAS REVISTAS ENTRE O PASSADO E O PORVIR
}

Fabiula dos Santos Schauffert ${ }^{1}$

Num mundo dominado pela técnica, em que novas tecnologias não cessam de serem superadas por outras inovações, tornando-se logo obsoletas, é espantoso verificar que ainda se continue a produzir e publicar poesia e revistas de poesia recorrendo-se ao recurso do velho papel. Convivendo com uma série de revistas eletrônicas e práticas poéticas que exploram os recursos dos meios digitais, estas revistas ainda apostam no antigo suporte e nas possibilidades que sua materialidade dispõe, a qual também passa a ser influenciada pelas inovações tecnológicas e pela mudança do suporte da escrita do papel para a tela do computador. É o que atestam as inúmeras publicações impressas no velho papel, de revistas literárias, de caráter independente, editadas por poetas, e não raro, dedicadas exclusivamente à poesia e a reflexão sobre poesia, que surgiram principalmente a partir dos anos 90 .

A leitura que aqui se pretende armar versará sobre duas dessas revistas, que surgiram com o novo século, Cacto, que traz no subtítulo - poesia \& crítica, nasceu em agosto, de 2002 e até agora chegou a quatro números (o quarto saiu em 2004) e Sibila - Revista de Poesia e Cultura, que apresenta uma proposta editorial mais interdisciplinar, publicando trabalhos visuais e assuntos ligados à cultura contemporânea de um modo geral, que surge no cenário dessas publicações em maio de 2001.

Ao contrário de Sibila, que investe em sofisticados recursos gráficos, trazendo em suas capas reproduções de trabalhos visuais, como fotografia, desenhos, que irão ser contemplados em suas páginas, Cacto apresenta-se de forma simples, não utilizando sofisticados recursos gráficos, nenhum recurso visual, somente as letras pretas sobre o papel e as capas coloridas em que se anuncia em preto o título da revista.

\footnotetext{
${ }^{1}$ Mestranda em Literatura Brasileira sob orientação de Profa $\operatorname{Dr}^{\mathrm{a}}$ Maria Lucia de Barros Camargo.
} 
No texto em que apresenta seu número inaugural, o qual não aparece assinado pelos seus editores, os poetas Eduardo Sterzi e Tarso de Melo, a Cacto deixa entrever que, apesar de ancorar-se no presente, não pode deixar de olhar para o passado, relembrando que antes dela já vieram muitas outras revistas literárias, voltadas à produção poética de seu tempo.

A revista, em seu primeiro número, pensa a si mesma como um veículo da poesia, inserindo-se numa tradição que vem do simbolismo e desemboca na contemporaneidade. Mais que um simples suporte da poesia, ela quer refletir acerca da própria historicidade, implícita no gesto de publicar uma revista de poesia.

Há cerca de cem anos é possível acompanhar a história da literatura brasileira quase que tão-somente pelas revistas produzidas a cada época: as simbolistas, as modernistas, as concretistas, as dos anos 70 , as contemporâneas. Por sua maior agilidade em relação aos livros, as revistas permitem que se apreenda uma imagem viva da poesia de uma época em seu processo de contínua formação e transformação. ${ }^{2}$

Ao reconhecer a importância dessas revistas que privilegiam a poesia, esboçando uma "imagem viva" dela, durante seu processo de transformação, ela o faz relembrando aquelas que vieram antes e ficaram conhecidas através do nome do movimento estético e literário que formaram e ajudaram a consolidar.

Ao se fincarem no presente, essas revistas não podem desvencilhar-se do passado, ele está inscrito em cada gesto que se configura na sua atualidade, seus vincos estão marcados em cada escolha, a começar pelo substantivo que as nomeiam. Ainda que não mencione, Cacto sugere a referência ao poema "O Cacto", de Manuel Bandeira, que tampouco faz menção a um poema de Eduardo Sterzi, intitulado "Outro cacto", que ao contrário estabelece uma referência direta ao poema de Bandeira. ${ }^{3}$

Sibila também traz em seu título o passado não somente por remeter ao mito, como também por desencadear referências enviesadas, mas que são

\footnotetext{
${ }_{3}^{2}$ Apresentação. Cacto - poesia \& crítica. n. 1.São Bernardo do Campo, 2002. p.5-6.

${ }^{3} \mathrm{O}$ poema não foi publicado na revista, foi encontrado no site: <http://www.avepalavra.kit.net/poesia2/poesianet198.htm> Acesso em 07 nov. 2007.
} 
entregues ao leitor no texto de abertura, publicado como o "Editorial"4, que abre seu primeiro número, o número "zero". Nele a revista, diretamente, expõe suas metas, diz a que veio, estabelece suas posições em relação à tradição literária e à poesia contemporânea e (des)venda o signo "Sibila" ao explicar por qual viés se apropria do nome da sacerdotisa e o reescreve na capa. Como revela ao leitor, a revista vai buscar seu nome no poema "Grafito para Giuseppe Capogrossi", do livro Convergência de Murilo Mendes.

O poema, publicado logo após o "Editorial", como se fosse parte dele, seu fechamento, foi eleito por configurar uma poética, que conjuga a reflexão sobre a linguagem e a criação literária, por apresentar uma linguagem que se liberta da referencialidade, coloca em crise o discurso, o qual descansa num referente, numa representação.

Se Sibila deixa explícito de que lugar da tradição "arranca" seu nome, Cacto parece querer ocultar ao leitor as referências que seu nome traz do passado (o poema de Manuel Bandeira) e do presente (o poema de Eduardo Sterzi), ao passo que evidencia os poetas Augusto e Haroldo de Campos, principalmente o primeiro, cujo poema "inédito", "Faça o que faça", abre a seção de poesia do primeiro número, o de "capa vermelha" 5.

Em seu ensaio sobre a trajetória de Augusto de Campos, em que analisa alguns poemas, apontando que este "era e é a rigor, o único que pode ser chamado integralmente de poeta concreto" ${ }^{6}$, Eduardo Sterzi, apesar de escrever um texto bastante teórico, começa com uma anedota, em que narra suas peripécias de leitor da poesia concreta, ainda adolescente, percorrendo bibliotecas atrás de material, questionando-se se haverá algum dia uma teoria da "paixão ou

\footnotetext{
${ }^{4}$ É importante notar que eles não são assinados pelos editores, que, nesse número eram Régis Bonvicino e Romulo Valle Salvino. Entretanto o principal editor é Régis Bonvicino, pois, esse é o único nome constante em todo o percurso da revista, já que a parceria com Salvino permanece até o quinto número, e com Odile Cisneros também aparece apenas em alguns números, sendo assim poderíamos dizer que a revista é do poeta e crítico Régis Bonvicino.

${ }^{5} \mathrm{~A}$ cor da capa remete à forma como Augusto de Campos se refere à revista dos concretos, Invenção 3 (1962), "o número vermelho", (mas o poeta parece ter se enganado, já que a revista Invenção de capa vermelha é a n.2), numa entrevista concedida a Eduardo Sterzi e Tarso de Melo. Ver em: Cacto - poesia \& crítica. n. 1. São Bernardo do Campo: Alpharrabio, 2002, p. 186.

${ }^{6}$ STERZI, Eduado. Sinal de Menos. Cacto - poesia \& crítica. n. 1. São Bernardo do Campo: Alpharrabio, 2002, p. 175.
} 
da simpatia literária" ${ }^{7}$, que explica o fato de certas obras tornarem-se totalmente relevantes para uns e irrelevantes para outros.

Se houvesse essa teoria, quem sabe então ela poderia nos explicar as escolhas da própria revista, o porquê da insistente homenagem que faz ao Concretismo, por meio de textos e cores, dado que as cores de sua capa do n.1 lembra a revista Invenção ${ }^{8}$ n. 2, a capa do n.3 é azul, da mesma cor da Invenção n.3, e por fim a do n.4 tem a mesma cor, laranja, da capa de Invenção n.4.

A revista em seu número inaugural não somente faz uma remissão ao passado, recordando as revistas de poesia que vieram antes, através do nome do movimento estético que se constituíram em torno delas, como também traz a mesma cor da capa da Invenção n.2, ao contrário da Invenção n.1, que privilegiava os textos teóricos, a de "capa vermelha" priorizava os textos de criação poética.

As revistas elegem uma certa linhagem da tradição literária, redesenhando momentos do passado, que convivem simultaneamente com a produção que se dá no presente. De maneira que, poderíamos conjugar esta concomitância do passado e do presente, com as modalidades ou os conceitos temporais, de potência e ato, pensados por Paolo Virno, em Recuerdo del presente. Esses conceitos antes de temporais são temporalizantes, empenham uma noção de tempo; passado e presente se desdobram nessas duas modalidades, potência e ato, ou por outra, virtual e atual, percepção e lembrança, que são duas formas de tentar apreender o fugidio "agora".

As revistas em sua forma de lidar com o passado e o seu legado realizam a operação temporal, que Virno tenta definir ao pensar a modalidade do possível e do real. Ao buscarem elementos do passado e os combinarem no presente, elas devolvem ao passado a modalidade da potência. O passado potencial não se esgota no ato, por isso sua forma pode ser definida a partir da faculdade da linguagem, que não se encerra no proferimento de uma sentença, da mesma

\footnotetext{
${ }_{8}^{7}$ A expressão é de Sterzi em Sinal de menos. op. cit., p. 174.

8 A revista Invenção, que sucedeu a Noigandres, trazia como subtítulo revista de arte de vanguarda; teve apenas cinco números, publicados entre 1962 e 1967; seus principais editores eram Haroldo e Augusto de Campos e Décio Pignatari.
} 
maneira, por extensão, a literatura e a linguagem poética são modalidades da potência, sua possibilidade de gerar sentidos não se encerra na leitura que se empreende.

Ao transporem o presente ao passado essas revistas realizam um procedimento contratemporal ou anacrônico, mas não se trata de um “anacronismo real”, como definiu Virno, em que a simultaneidade de potência e ato são tidas como repetição de um evento do passado, e sim de um "anacronismo formal", que insere os eventos agora experimentados no passado potencial, aplicando a forma-passado ao presente em curso.

De alguma maneira este procedimento é confirmado também pela revista Sibila, principalmente quando ela afirma ser o passado o lugar do novo,

\begin{abstract}
ao mesmo tempo em que se dispõe a trazer o extremamente novo, o contemporâneo aquilo que ainda é uma aposta, também não há como sepultar o passado e, por isso, está aberta a ele não como um conjunto de verdades, mas como repertório de mensagens outras, tesouro de interrogações, espaço de sempre novidades ${ }^{9}$.
\end{abstract}

Após a experiência das vanguardas, falar em novo hoje pode parecer anacrônico, mas ao trazê-lo para o presente a revista o desloca de quaisquer acepção dogmática que as vanguardas deram ao termo. Em seu projeto voltado para o futuro, em seu culto ao novo e em sua crença no progresso, elas estavam desde o início fadadas ao seu fim. As vanguardas levaram a idéia do novo ao esgotamento; vinculado ao modelo de progresso científico, o novo passou a atuar também nas artes e na literatura, de maneira que, tornou-se um esquema de desenvolvimento estético, acenando para a possibilidade de uma estética do novo, entendida como uma estética da mudança e da negação ${ }^{10}$. Um certo modo de ser vanguarda começou a manifestar seu esgotamento a partir dos anos 60, mas a decadência da estética do novo "foi preparada por uma fabulosa precipitação da renovação desde a Segunda Guerra Mundial. Adorno via essa aceleração como uma conseqüência inelutável da estética do novo, resultando de sua relação

\footnotetext{
${ }^{9}$ Sibila - Revista de Poesia e Cultura. n.0. São Paulo: Ateliê Editorial, 2001, p.7.

${ }^{10}$ Idem, p. 20.
} 
equívoca com o mercado." 11 A busca do novo que havia se tornado o imperativo da arte, é também o imperativo do mercado capitalista. Dessa forma a estética do novo é ambígua, podendo ser explica tanto como resultante do domínio do novo no mercado, quanto como resistência às suas leis. ${ }^{12}$

Pelo tempo que nos separa das vanguardas históricas e da exaustão do novo, a que chegaram, os sentidos que o novo acarreta na contemporaneidade não são mais os mesmos, hoje o novo soa como fora do tempo, esmorecido. Podemos dizer, com Compagnon, que o novo "atualmente, vai mal, talvez esteja morto". 13

Consciente dessas implicações do novo, a revista o desvincula de qualquer noção de superação e progresso - o novo é entendido como o contemporâneo, a recombinação de elementos há muito já estabelecidos na tradição literária.

Há uma recusa em reativar as doutrinas vanguardistas, como se pode ver na Cacto e na Sibila. Cada uma a sua maneira, por viés diferente, reafirma a falência das vanguardas e da estética do novo. Entretanto, Sibila ainda fala em "novas possibilidades", em "inovação", mas faz questão de relativizar ou contemporaneizar esses termos. Já a Cacto parece silenciá-los, prefere não reativá-los, no entanto, na "Apresentação" de seu segundo número, ela afirma que seu "projeto mínimo", é "resolutamente desafeito ao sectarismo, interessado antes na poesia que possa haver, e há"14.

Ao rejeitar a idéia de grupos fechados em certas tendências, colocando-se aberta a possíveis "intercâmbios", Cacto se recusa a preestabelecer critérios e valores que possam sugerir um certo tipo de militância estética, tal como se via nas revistas literárias que se tornaram signos de movimentos vanguardistas, apesar de homenagear em cores a revista concretista Invenção, que substituiu a Noigandres.

\footnotetext{
${ }^{11}$ Idem, p. 81.

12 Idem, p.61.

${ }^{13}$ COMPAGNON, Antoine, op.cit., p. 80.

${ }^{14}$ Cacto - poesia \& crítica. n. 2. São Bernardo do Campo: Alpharrabio, 2003, p. 6.
} 
Compagnon, ao escrever sua narrativa contraditória (ou paradoxal) da modernidade, que parte dos primeiros modernos (Baudelaire e Manet) até passar pelas vanguardas, pela art pop e a pela arquitetura pós-moderna, para desembocar, enfim, ou retornar, a Nietzsche e Baudelaire, os primeiros a desconfiar do progresso e do entusiasmo do novo, mapeia a história do termo pósmoderno, na arquitetura, na literatura e nas artes plásticas e até mesmo na filosofia, mostrando que os sentidos estéticos do pós-moderno na arquitetura têm uma correspondência com a literatura.

$\mathrm{Na}$ arquitetura, "o pós-modernismo reavalia a ambigüidade, a pluralidade e a coexistência dos estilos; cultiva ao mesmo tempo a citação vernácula e a citação histórica. A citação é a mais poderosa figura pós-moderna."15 $\mathrm{O}$ movimento pósmoderno se insurge contra a concepção estética do modernismo; "contra o dogma da tábula rasa e da renovação constante, contra a busca da unidade e da identidade" ${ }^{16}$. Tentando romper com os princípios vanguardistas, o pós-moderno revela seu paradoxo - "reproduz a operação moderna por excelência: a ruptura" ${ }^{17}$.

As revistas ao negarem certos princípios que as colocariam na mesma série das revistas de vanguarda, rompem com eles e reproduzem o procedimento que definia as vanguardas. A citação que é uma figura da pós-modernidade, também está presente nelas, tanto no que evocam através de seus nomes, quanto pela revisitação a textos que já fazem parte da tradição literária.

A narrativa de Compagnon deságua no último paradoxo, no crepúsculo do novo - "a fé do novo repousava sobre tantas contradições que ela se destruiu por si mesma, e o círculo parece estar inteiramente terminado: da ruptura com a tradição à tradição da ruptura e por fim, à ruptura com a ruptura, que seria a nossa pós-modernidade." 18

A reflexão sobre o fim das vanguardas e o novo é recorrente na revista Sibila, que na capa de seu número inaugural traz destacado em laranja o título "O

\footnotetext{
${ }^{15}$ COMPAGNON, Antoine, op.cit., p.109.

${ }^{16}$ Idem, p.107.

${ }^{17}$ Idem, p. 105.

${ }^{18}$ Idem, p.124.
} 
fim das vanguardas como elas eram" e no seguinte número (n.1) publica um texto de Romulo Valle Salvino, intitulado "Algumas palavras sobre as vanguardas."

A revista, através da voz de um de seus editores, então, afirma que ainda é possível fazer a idéia do novo e de vanguarda operar, ainda que sob outros procedimentos. Para ativar a noção de vanguarda, deve-se considerá-la por "contraste e não definindo uma categoria histórica ou uma determinada sensibilidade estética - visto que, qualquer noção de estética demanda o novo, isto é, algo que rompa uma percepção cristalizada, seja qual for o nome dado a ele" 19 .

O contraste se dá de duas maneiras, segundo o crítico: primeiramente, mediante a "possibilidade de relação de uma forma artística da atualidade e uma outra do passado", mas a recriação de formas do passado não deve se dar acriticamente, devendo possibilitar a captura do presente. "O novo já pode ter acontecido em algum momento do passado, mas só é novo se estiver em consonância com o presente." ${ }^{20}$ A outra forma de contraste estaria no fato de a arte responder às questões de seu próprio tempo.

O novo é entendido como aquilo que traz inscrito em si o seu próprio tempo; o novo, agora, seria uma estética do presente, consonante àquilo que defendiam, segundo Compagnon, os primeiros modernos, Coubert e Manet, Flaubert e Baudelaire,

não encontramos em nenhum deles o traço que se tornou, a nossos olhos, característico da modernidade como retórica da ruptura e mito do começo absoluto, traço esse que nos leva a identificá-la com o militantismo do futuro: a consciência de um papel histórico a desempenhar. Os primeiros modernos não procuravam o novo num presente voltado para o futuro e que carregara consigo a lei de seu próprio desaparecimento, mas no presente enquanto presente. Essa distinção é capital. Eles não acreditavam, como disse, no dogma do progresso, do desenvolvimento e da superação. ${ }^{21}$

\footnotetext{
${ }^{19}$ SALVINO, Romulo Valle. Algumas palavras sobre as vanguardas. Sibila - Revista de Poesia e Cultura. n.1. São Paulo: Ateliê Editorial, 2001, p. 54.

${ }^{20}$ Idem, p.61.

${ }^{21}$ COMPAGNON, Antoine. Os cinco paradoxos da modernidade. Trad. Cleonice P. Mourão. Belo Horizonte: Editora UFMG, 1996, p.37.
} 
Com isso, a revista parece refletir o desfecho da narrativa de Compagnon - o "retorno a Baudelaire" -, visto que, a modernidade é por ele identificada com a paixão do presente, ao passo que as vanguardas com seu projeto voltado para o futuro, já não podem nem sequer olhar para o presente.

Nesse sentido, tanto Cacto quanto Sibila parecem ser movidas por uma "paixão do presente", fincadas no presente, privilegiando a arte de seu tempo, sem um fim voltado para o futuro, sem acreditar em evolução, progresso, sem fazer tábula rasa do passado. 


\section{REFERÊNCIAS}

Cacto - poesia \& crítica. n. 1. São Bernardo do Campo: Alpharrabio, 2003.

Cacto - poesia \& crítica. n. 2. São Bernardo do Campo: Alpharrabio, 2003.

Cacto - poesia \& crítica. n. 3. São Bernardo do Campo: Alpharrabio, 2003.

COMPAGNON, Antoine. Os Cinco Paradoxos da Modernidade. Trad. Cleonice P. Mourão. Belo Horizonte: Editora UFMG, 1996.

Invenção. n.2. São Paulo: Massao Ohno Editora, 1962.

Invenção. n.3. São Paulo: Invenção, 1963.

Invenção. n. 4. São Paulo: Invenção, 1964.

Sibila - Revista de Poesia e Cultura. n.0. São Paulo: Ateliê Editorial, 2001.

Sibila - Revista de Poesia e Cultura. n.1. São Paulo: Ateliê Editorial, 2001.

Sibila - Revista de Poesia e Cultura. n.2. São Paulo: Ateliê Editorial, 2002.

Sibila - Revista de Poesia e Cultura. n.3. São Paulo: Ateliê Editorial, 2002.

Sibila - Revista de Poesia e Cultura. n.4. São Paulo: Ateliê Editorial, 2003.

Sibila - Revista de Poesia e Cultura. n.4. São Paulo: Ateliê Editorial, 2003.

Sibila - Revista de Poesia e Cultura. n.5. São Paulo: Ateliê Editorial, 2003.

Sibila - Revista de Poesia e Cultura. n.6. São Paulo: Ateliê Editorial, 2004.

Sibila - Revista de Poesia e Cultura. n.7. São Paulo: Ateliê Editorial, 2004.

Sibila - Revista de Poesia e Cultura. n.8-9. São Paulo: Ateliê Editorial, 2005. 